\title{
Über die Bestimmung der enzymatischen Wirkung der Nuclease mittels xoptischer Methode».
}

$$
\text { Von }
$$

Dr. Giacomo Pighini,

Direktor des wissenschaftlichen Laboratoriums des psychiatrischen Instituts Reggio Emilia.

Mit 14 Kurvenzeichnungen im Text.

(Der Redaktion zugegangen am 22. September 1910.)

In letzter Zeit hat in der Biochemie und Pathologie das Studium der Nuclease und der Purinfermente im allgemeinen eine besondere Bedeutung bekommen.

Nebst der von Fr. Sachs und Iw an off entdeckten Enzymgruppe, welche Nucleinsäure in Purin- bezw. Pyrimidinbasen, Pentosen und Phosphorsäure abbaut, wurden andere hydrolysierende und oxydierende Fermente nach und nach entdeckt, welche auf die von der Nuclease abgebauten Purinbasen wirken und sie in Harnsäure transformieren.

Man könnte also den enzymatischen Prozeß der Harnsäureentstehung im tierischen Organismus beziehen auf:

a) Die Nuclease, welche die Nucleinsäure hydrolysiert, indem sie die Purinbasen loslöst;

b) zwei desamidierende Fermente (Amidasen), die Guanase und die Adenase, welche die $\mathrm{NH}_{3}$-Gruppe der Aminopurine loslösen und dieselben in die korrespondierenden $0 \mathrm{xy}-$ purine überführen;

c) ein oxydierendes Ferment - Xanthinoxydase welches das Hypoxanthin und das Xanthin zu Harnsäure ${ }^{1}$ ) oxydiert.

1) Winternitz und Jones, Diese Zeitschrift, Bd. LX, 1909, S. 180. Bloch, Biochem. Zentralbl., Bd. V.

Hoppe-Seyler's Zeitschrift f. physiol. Chemie. LXX. 
Die Nuclease, von Salkowski ${ }^{1}$ ) und von Hahn und Geret ${ }^{2}$ ) in ihren enzymatischen Eigenschaften gut studiert, wurde nach und nach in vielen Extrakten von tierischen Organen und Geweben, in den Pflanzenorganen, in den keimenden Samen, in den Pilzen, in den Hefen gefunden; man hat also ihre große Verbreitung in der lebenden Natur erkannt, sowie ihren wichtigsten Dienst, den Auf bau und den Abbau der Nucleoproteide ${ }^{3}$ ) zu vollziehen. So wurden auch in den verschiedenen Organen die anderen Fermente gefunden, welche den von der Nuclease angefangenen Abbau vollenden und die Purinbasen desamidieren und oxydieren.

Die Art der Untersuchung, die bis jetzt beim Studium der Nuclease (mit diesem Enzym beschäftigen wir uns jetzt hauptsächlich) angewandt wurde, war meistens folgende: Die Extrakte der Gewebe wurden mit Nucleinsäure oder nucleinsaurem Natron in Berührung gebracht und nachdem sie 1-2 Tage im Brutofen gestanden hatten, das Vorhandensein der Purinbasen und die Bildung von Phosphorsäure festgestellt. Solch ein Versuch dient freilich zu einer quantitativen Orientierung über die abgebauten Substanzen sehr gut, ist aber nicht zum Studium der spezifischen Fermentwirkung der Organextrakte geeignet, da man zu diesem Zwecke nach bestimmten Zeiten mühsame chemische Untersuchungen vornehmen muß, deren guter Erfolg von bedeutenden Quantitäten von Material und viel Zeitaufwand abhängig ist.

Es ist mir tatsächlich unbekannt, ob jemand bis jetzt die spezifische fermentative Wirkung der Nuclease aus bestimmten Extrakten mit chemischen Methoden untersucht hat, und ich glaube auch nicht, daß andere Methoden zum Studium dieses wichtigen Phänomens angewandt worden sind.

$\mathrm{Da}$ ich in der Lage war, die Wirkung der Nuclease in dem Serum des Blutes von verschiedenen Kranken unseres Instituts zu beobachten und zwar für besondere Untersuchungen,

1) Diese Zeitschrift, Bd. XIII.

2) Ber. d. Deutsch. chem. Ges., Bd. XXI.

3) Zaleski, Botanische Berichte, Bd. XXV. 
die ich später mitteilen werde, habe ich auch quantitative chemische Methoden angewandt und ab und zu die Phosphorsäure und die Xanthinbasen - von der Serummischung und der Nucleinsäure befreit - untersucht.

Aber außer dem Nachteil des langen Zeitaufwandes hat diese Untersuchung nie befriedigende Resultate ergeben.

Ich dachte also, die polarimetrischen Messungen anzuwenden, und da ich sehr befriedigende Resultate damit erhalten habe, glaube ich nun die "Optische Methode» als die geeignetste zu dem Studium der Nuclease und ihrer enzymatischen Wirkung auf organische Gewebe und Flüssigkeiten empfehlen zu können.

Die «optische Methode», wie bekannt, schon seit langem beim Studium der Enzyme, der Disaccharide und Glukoside angewandt, wurde auch mit Erfolg für die Erforschung der proteolytischen Enzyme (E. Schütz, Huppert) verwertet, und in den Händen von $\mathrm{Abderhalden}$ und seinen Mitarbeitern erweist sie der Wissenschaft die nützlichsten Dienste.

Wie in den Versuchen Abderhaldens die proteo-peptolytischen Fermente auf die optisch aktiven Polypeptide wirken, so wirkt die Nuclease auf die Nucleinsäure. Die reine Nucleinsäure dreht in der Tat, wie Jones bewiesen hat, ${ }^{1}$ ) die Ebene des polarisierten Lichtes nach rechts, und solche Drehung hängt von der Konzentration und dem Grade der Acidität resp. der Alkalescenz der Lösung ab. Unter der Wirkung des spezifischen Fermentes wird die Nucleinsäure nach und nach in ihre konstitutiven Elemente abgebaut - Purinbasen, Pentosen, Phosphorsäure - und verliert zu gleicher Zeit ihre optischen Eigenschaften.

Die Abnahme des Drehungswinkels im Verhältnis zur Zeit, bei konstanter Temperatur, gibt ein genaues Maß der Wirkung der in einer bestimmten Flüssigkeit oder einem Extrakt enthaltenen Nuclease.

Meine Versuche beschränken sich vorläufig auf Serum

1) W. Jones, On the identity of the nucleic acids of the Thymus, Spleen and Pancreas. The journal of biological chemistry, Bd. V, S. 11, 1908. 
vom Blut einiger Säugetiere. Man kann aber dieselben Versuche auch mit klaren farblosen oder kaum gefärbten Extrakten von Organen machen, in denen man die Nucleasewirkung untersuchen will.

Steril entnommenes Venenblut wird 24 Stunden stehen gelassen oder zentrifugiert. Das Serum wird dann herauspipettiert und mit klaren und filtrierten Lösungen von Nucleinsäure gemischt.

Für meine Versuche habe ich immer Nucleinsäure Merck (aus Hefe) in physiologischer Kochsalzlösung mit Natronlauge oder Ammoniak schwach alkalisch gemacht gebraucht.

Als die für Serum geeignetste Lösung ist mir folgende erschienen: $1,60 \mathrm{~g}$ Nucleinsäure Merck, $100 \mathrm{~g}$ physiologische Kochsalzlösung (0,85\% ig), 12 Tropfen Ammoniak. An Stelle von Ammoniak kann 5\% ige Natronlauge genommen werden (25-30 Tropfen), ohne daß die Resultate sich sehr viel ändern.

Wenn aber Vergleichsversuche gemacht werden sollen, ist es nötig, immer dieselben Mengenverhältnisse anzuwenden.

Von der Nucleinsäurelösung wird eine dem Volumen des Polarimeterrohres entsprechende Menge abgemessen, 1 - besser 2 - ccm zugefügt, gut gemischt und bei Zimmertemperatur polarisiert.

Das Rohr wird dann in einen Ostwaldschen Thermostaten bei $37^{\circ}$ hineingetaucht und der Inhalt nach bestimmten Zeiten polarimetrisch untersucht, nachdem man es auf Zimmertemperatur $\left(18-20^{\circ}\right)$ abgekühlt hat.

Die Untersuchung gelingt aber besser, wenn man die Temperatur des Rohres im Polarimeter selbst auf $37^{\circ}$ hält.

Bei meinen Untersuchungen habe ich ein Polarimeter nach Laurent (10 cm-Rohr) und ein Saccharimeter nach Soleil mit bunten Gläsern ( $22 \mathrm{~cm}-\mathrm{Rohr}$ ) gebraucht, welches, obwohl nicht sehr genau, für die gefärbten Sera doch die besten Resultate geben kann.

Jeder Versuch war gleichzeitig von einem Kontrollversuch begleitet, bei dem das Serum durch ein gleiches Quantum physiologischer Kochsalzlösung ersetzt war.

Ich werde nun einige meiner Untersuchungen illustrieren. 
Über die Bestimmung der enzymatischen Wirkung der Nuclease.

Fig. 1 (Saccharimeter Soleil)

$2 \mathrm{ccm}$ Serum von erwachsenem Kaninchen,

22 > Lösung von $1,60 \mathrm{~g}$ Nucleinsäure Merck in $100 \mathrm{ccm}$ physiologischer Kochsalzlösung +12 Tropfen $\mathrm{NH}_{3}$.

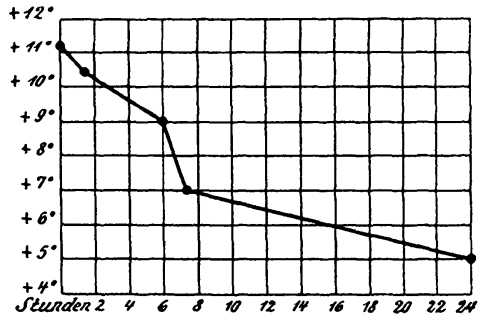

Fig. 2 - Kontrollversuch (Saccharimeter).

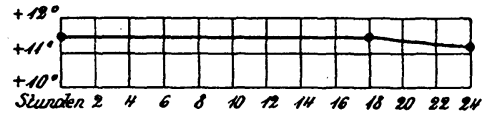

Fig. 3 (Saccharimeter).

$2 \mathrm{ccm}$ Serum von jungem Kaninchen,

22 - Lösung von 1,60 g Nucleinsäure in $100 \mathrm{ccm}$ physiologischer Kochsalzlösung +12 Tropfen $\mathrm{NH}_{3}$.

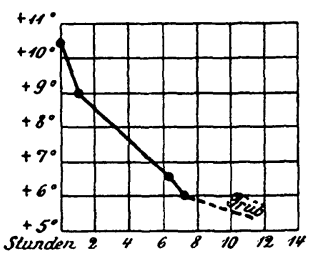

Fig. (Polarimeter Laurent).

2 ccm Kalbsserum,

22 , Lösung von $1,60 \mathrm{~g}$ Nucleinșäure in $100 \mathrm{ccm}$ physiologischer Kochsalalösung +12 Tropfen $\mathrm{NH}_{3}$.

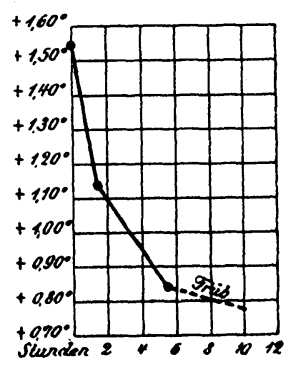

Fig. 5 (Polarimeter).

$2 \mathrm{ccm}$ Ochsenserum,

22 , Lösung von $1,60 \mathrm{~g}$ Nucleinsäure in $100 \mathrm{ccm}$ physiologischer Kochsalzlösung +12 Tropfen $\mathrm{NH}_{8}$.

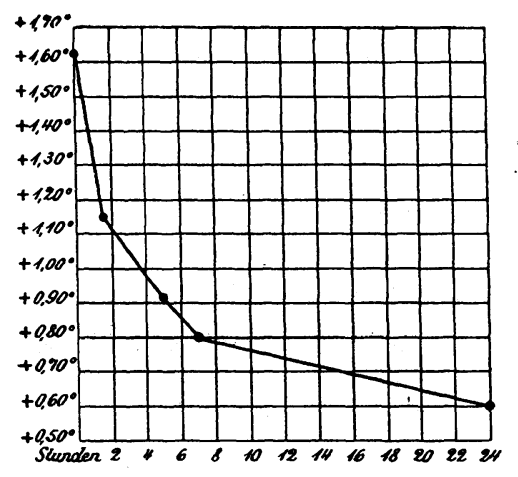


Fig. 6 (Polarimeter).

$2 \mathrm{ccm}$ Ochsenserum,

22 \ Lösung von 1,60 g Nucleinsäure in $100 \mathrm{ccm}$ physiologischer Kochsalzlösung +28 Tropfen 5\% iger $\mathrm{NaOH}$.

Fig. 7 (Polarimeter).

$2 \mathrm{ccm}$ Ochsenserum.

22 L Lösung von 1,60 g Nucleinsäure in $100 \mathrm{ccm}$ physiologischer Kochsalzlösung +34 Tropfen 5\% iger $\mathrm{NaOH}$.
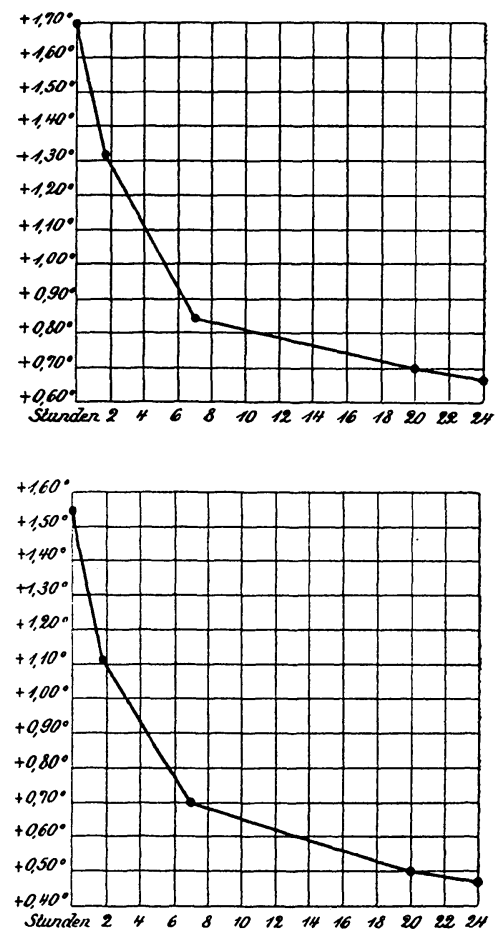

Fig. 8 (Saccharimeter).

2 ccm Kalbsserum,

22 , Lösung von $1,60 \mathrm{~g}$ Nucleinsäure in $100 \mathrm{ccm}$ physiologischer Kochsalzlösung +12 Tropfen $\mathrm{NH}_{3}$.

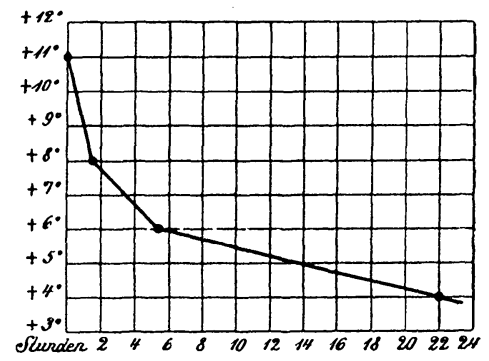

Fig. 9 (Saccharimeter).

2 ccm Kalbsserum,

22 Lösung von $1,60 \mathrm{~g}$ Nucleinsäure in $100 \mathrm{ccm}$ physiologischer Kochsalzlösung +12 Tropfen $\mathrm{NH}_{3}$.

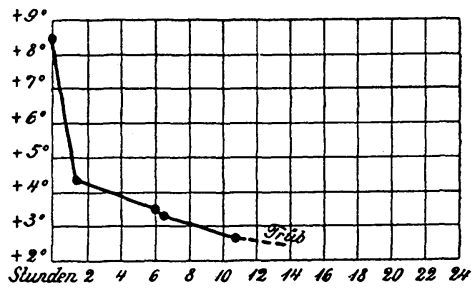


Über die Bestimmung der enzymatischen Wirkung der Nuclease. 91

Fig. 10 (Saccharimeter).

$2 \mathrm{ccm}$ Ochsenserum,

22 > Lösung von $1,60 \mathrm{~g}$ Nucleinsäure in $100 \mathrm{ccm}$ physiologischer Kochsalzlösung +12 Tropfen $\mathrm{NH}_{8}$.

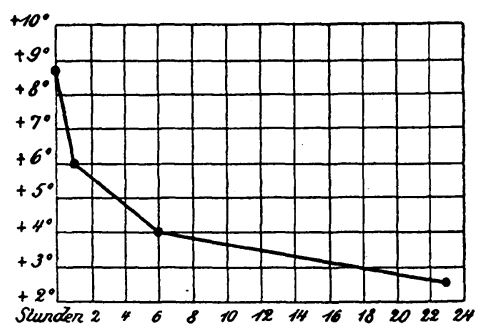

Fig. 11 (Saccharimeter).

2 ccm Ochsenserum,

22 . Lösung von $1,60 \mathrm{~g}$ Nucleinsäure in $100 \mathrm{ccm}$ physiologischer Kochsalzlösung +12 Tropfen $\mathrm{NH}_{s}$.

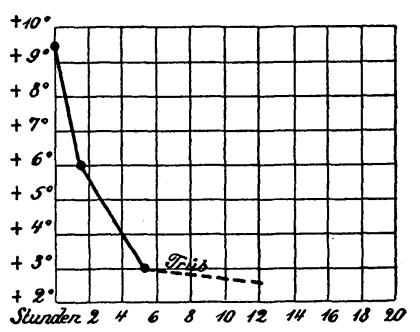

Fig. 12 (Polarimeter).

$2 \mathrm{ccm}$ Serum eines normalen Menschen,

22 . Lösung von $1,60 \mathrm{~g}$ Nucleinsäure in $100 \mathrm{ccm}$ physiologischer Kochsalzlösung +12 Tropfen $\mathrm{NH}_{3}$.

Fig. 13 (Saccharimeter).

$2 \mathrm{ccm}$ Serum eines epileptischen Menschen,

22 - Lösung von $1,60 \mathrm{~g}$ Nucleinsäure in $100 \mathrm{ccm}$ physiologischer Kochsalzlösung +12 Tropfen $\mathrm{NH}_{8}$.
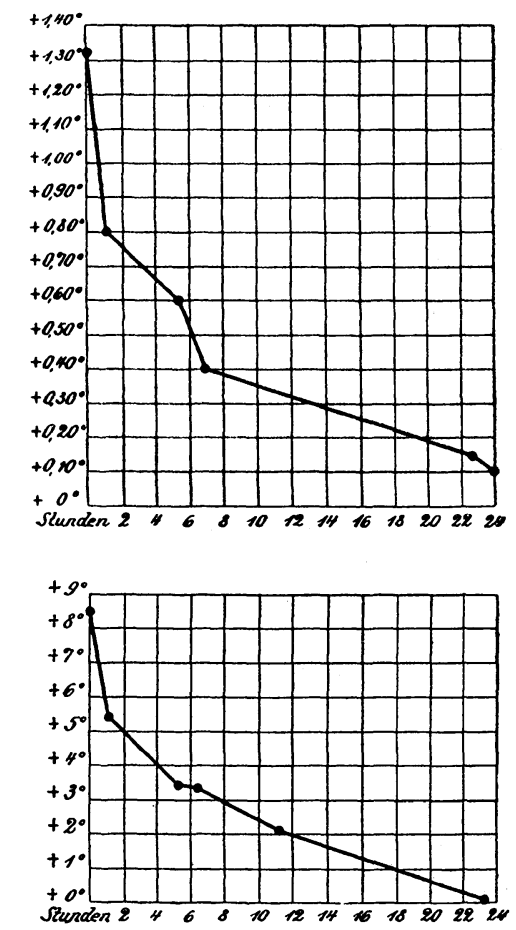
Aus diesen Untersuchungen ergibt sich, daß die in dem Serum des Blutes enthaltene Nuclease auf die Nucleinsäure wirkt, indem sie sie spaltet und langsam ihr Drehungsvermögen vermindert, bis es ganz verschwunden ist.

Beim Polarisieren wurde durchweg Natriumlicht benutzt. Die Kurven in den Tabellen beweisen, daß die Wirkung der Nuclease ununterbrochen ist, stärker in der ersten Stunde, allmählich schwächer werdend in den folgenden Stunden.

Aus den graphischen Darstellungen ergibt sich, daß kein großer Unterschied zwischen den verschiedenen Sera in ihrem Verhalten zur angewandten Nucleinsäure vorliegt; eine stärkere Wirkung zeigt sich in dem menschlichen Serum. Die Sera von jungen Tieren zeigen eine größere Neigung zur Trübung.

Wenn man aber genaue Vergleichsversuche machen muß, wird es gut sein, die Geschwindigkeitskonstante

$$
k=\frac{1}{t} \log \frac{a}{a-x}
$$

zu berechnen.

Die spezifische fermentative Wirkung der geprüften Sera ist bewiesen durch immer gleichzeitig angestellte Kontrollversuche (Fig. 2), sowie durch andere Untersuchungen, die den Zweck hatten, das Ferment im Serum zu vernichten, ehe man dieses auf die Nucleinsäure wirken ließ. Auf $65^{\circ}$ erhitzte Sera verlieren fast alle ihre fermentative Wirkung.

Fig. 14 (Saccharimeter).

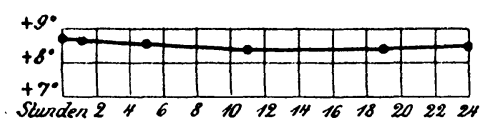

$2 \mathrm{ccm}$ menschlichen Serums auf $65^{\circ}$ erhitzt,

22 . Lösung von 1,60 g Nucleinsäure in $100 \mathrm{ccm}$ physiologischer Kochsalzlösung +12 Tropfen $\mathrm{NH}_{3}$.

Die «optische Methode», auf die Untersuchung der fermentativen Wirkung der Nuclease übertragen, hat uns die besten Resultate gegeben und scheint die geeignetste für dieses Studium. 
Über die Bestimmung der enzymatischen Wirkung der Nuclease. 93

Es eignet sich daher - wie wir in nächsten Mitteilungen sehen werden - zu vergleichenden Untersuchungen der Nucleasewirkung in den verschiedenen normalen und pathologischen Sera resp. Organextrakten und zu dem Studium der Aktivatoren (Ko-Enzyme), der Paralysatoren und der spezifischen Gifte, welche auf das Ferment wirken. 